\title{
The Effect of Aluminum Dihydrogen Phosphate on the Enhanced Mechanical Properties of Aluminum Foams
}

\author{
Qiang Feng ${ }^{1, *}$, Xueyan $\mathrm{Wu}^{2}$, Yanning Guo ${ }^{1}$, Jia $\mathrm{She}^{3}$ and Yong Xiang ${ }^{1}$ \\ ${ }^{1}$ College of Physics and Engineering, Chengdu Normal University, 99 East Haike Road, Chengdu 611130, Sichuan, P. R. China \\ ${ }^{2}$ School of Materials Science and Engineering, Shanghai Jiao Tong University, 800 Dongchuan Road, Shanghai 200240, P. R. China \\ ${ }^{3}$ School of Materials Science and Engineering, Chongqing University, Chongqing 400044, P. R. China
}

Powder metallurgy route was employed to fabricate aluminum ( $\mathrm{Al})$ foams with open and small cells. Starch acetate powder was adopted as a space holder, which evaporates during carbonization and leaves behind pores in the Al matrix. Aluminum dihydrogen phosphate (ADP) was used as binding agent between $\mathrm{Al}$ particles in present work. Cell diameters of $\mathrm{Al}$ foams range from several microns to thousands of microns, and cell geometry depends mainly on the distribution of starch acetate particles during mixing process. The phase compositions were characterized by X-ray diffraction (XRD). The scanning electron microscopy (SEM) together with energy dispersive X-ray spectroscopy (EDS) suggests the existence of carbon produced along cell wall after annealing. Subsequently, a uniaxial compression test was performed to study the effect of ADP content on mechanical properties and absorption abilities of Al foams. It is shown that both mechanical property and energy absorption ability are improved with appropriate amount of ADP. [doi:10.2320/matertrans.M2017247]

(Received November 21, 2017; Accepted March 29, 2018; Published May 11, 2018)

Keywords: aluminum foams, space holder, aluminum dihydrogen phosphate, powder sintering, absorption ability

\section{Introduction}

Al foams have attracted considerable attention for applications in fields of military and commercial industries in recent years due to their low density, splendid strength and stiffness to weight ratios, exceptional mechanical energy absorption to impact, excellent sound absorption and good insulation properties. ${ }^{1-6)}$ Generally, open cells with small diameters in Al foams are in demand for functions such as filtration, separation, thermal dissipation, heat insulation, and energy or sound absorption.

Various methods for the preparation of open-cell $\mathrm{Al}$ foams such as preform infiltration, and investment casting, have been widely developed. ${ }^{7,8)}$ Since foam structure parameters like cell shape, cell size and porosity, are dependent highly on the space holder, there are still some imperfections to the structures by the liquid infiltration process engineering. The space holder should not only possess high melting point, but also can be eliminated utilizing dissolution. Powder metallurgy route is another promising route for manufacturing open-cell Al namely sintering and dissolution process. ${ }^{9)}$

$\mathrm{NaCl}$ powder was once used as a filler material in sintering and dissolution process. Sintering and clearing away salt particles for Al foam manufacture is a cost-effective method with controlled porosity, cell size, and cell shape. Nevertheless, complete dissolution of $\mathrm{NaCl}$ consumes a significant amount of time and any residual $\mathrm{NaCl}$ may cause the contamination or corrosion of the body material. Ammonium bicarbonate and carbamide powder was also filler materials for porous metal preparation, but both of them decompose easily before the formation of strong bonding between metal particles. Obviously, it is difficult to control the cell shape since the porous metal structure is prone to collapse. ${ }^{2,7)}$ Cenosphere $^{10)}$ and saccharose ${ }^{11)}$ were also introduced as space holders in metal foams manufacture. Up

*Corresponding author, E-mail: fengqcdnu@126.com to now, very few people chooses starch acetate to make $\mathrm{Al}$ foam. Starch acetate has long been considered as potential material for biodegradation in food packaging and diverse biomedical applications owing to its low cast. ${ }^{12}$ )

Powder metallurgy route such as compression and sintering is not suitable for Al alloys because the compressive strength is too low to break the oxide layer formed on the surface which prevents diffusion bonding in the process of sintering. ADP is a kind of thermosetting material whose cementation mechanism belongs to condensation polymerization. Very few study has been carried out to make Al foam with starch acetate as a space holder and to examine the effect of ADP on the compressive behavior of these foams till to date. In this paper, we focused on the preparation of $\mathrm{Al}$ foam using starch acetate as a filler material for desired porosity. Emphasis was placed mainly on the influence of ADP content on both microstructure and corresponding compressive deformation response.

\section{Experimental}

Typical morphologies of starch acetate powder particles used in present investigation are shown in Fig. 1. It can be seen that the diameter of starch acetate particles ranges from hundreds of microns to thousands of microns. Dual steps of mixing were carried out. Firstly, ADP and Al (purity of 99.5\%, 300 mesh) powder were agitating milled until ADP was attached to Al particles uniformly. Starch acetate powder was then added for the second agitating process. After that, the mixture was uniaxially cold compacted for $10 \mathrm{mins}$ in a cylindrical die cavity with a hydraulic press at a speed of $0.1 \mathrm{~mm} / \mathrm{s}$ and a pressure of $250 \mathrm{MPa}$ to ensure effective pressurization and densification of the cold compacted pellets. Cylindrical green compacts with a diameter of $20 \mathrm{~mm}$ and a height of $15 \mathrm{~mm}$ were prepared. Desired volume of porosity in the foams would be obtained due to destruction-carbonification of starch acetate. Initial 


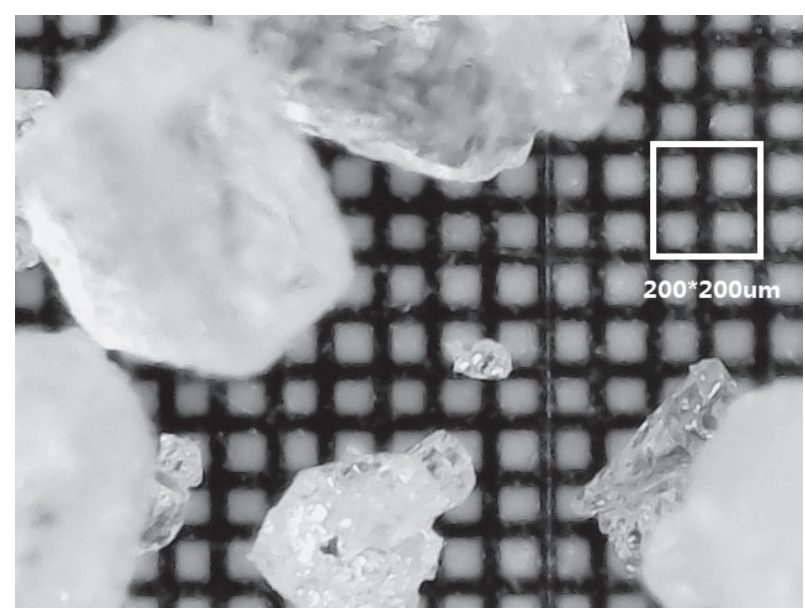

Fig. 1 Optical micrographs of starch acetate powder particles.

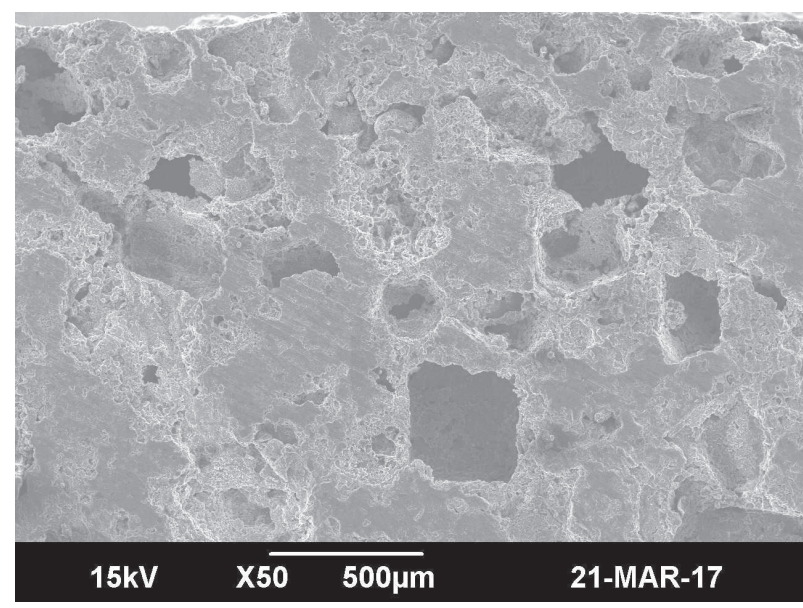

Fig. 2 SEM macrograph of $\mathrm{Al}$ foam structure. components of the powder were mixed to prepare precursors with identical dimensions for all compositions (Al34.0 mass $\%$ starch acetate, with 0, 4.0, 7.5 and 11.0 mass $\%$ of ADP, respectively).

Although initial degradation of starch acetate happens at the temperature of approximately $300^{\circ} \mathrm{C}$, the cold compacted pellets were still dried at $200^{\circ} \mathrm{C}$ in an evacuated quartz tube for $1 \mathrm{~h}$ to remove water adsorbed in their structure. ${ }^{12,13)}$ The pellets were then heated at $400^{\circ} \mathrm{C}$ for $2 \mathrm{~h}$ to remove water produced by destruction-carbonification of starch acetate, followed by a $2 \mathrm{~h}$ sintering at $620^{\circ} \mathrm{C}$ and cooling down to ambient temperature. The XRD data of sintered specimens were collected on a X-ray diffractometer (BRUKER, D8 Advance). SEM analyses were obtained from a JSM 6390A electron microscope (Japan) in conjunction with EDS. The compressive specimens were cut into cylinder with $15 \mathrm{~mm}$ in diameter and $15 \mathrm{~mm}$ in height. ${ }^{14)}$ Sample compression tests were performed on a $10 \mathrm{KN}$ Servohydraulic universal testing machine WAW-100B material testing system with a crosshead speed of $0.5 \mathrm{~mm} / \mathrm{min}$ at room temperature.

\section{Results and Discussion}

Typical macroscopic structure of the present open-cell Al foam obtained from powder sintering process in an evacuated quartz tube is shown in Fig. 2. The formed cells have diameters ranging from several to thousands of microns, and their geometry depends mainly on the distribution of starch acetate particles in compacted precursors. It can be observed clearly from Fig. 2 that the open cells are interlinked by the interconnecting cell channels. When the weight fraction of starch acetate powder is beyond a certain level, most starch acetate particles are in contact with each other and a consecutive three-dimensional network would be formed. Conversely, some starch acetate particles are enclosed completely by the Al matrix as the starch acetate weight fraction is lower. The isolated starch acetate particles would form some closed pores in the foam. Naturally, small amount of residual carbon remains in the resultant foam after the carbonization of the starch acetate during heat treatment. If taking no account of the porosity forming from the composition content of ADP, the following equation can be used to calculate the weight of different component in the compact to achieve a definite porosity:

$$
W_{A l}: W_{S A}=\rho_{A l}\left(1-V_{S A}\right):\left(\rho_{S A} * V_{S A}\right)
$$

where, $\mathrm{W}_{\mathrm{Al}}$ represents weight of $\mathrm{Al}$ powder samples. $\mathrm{W}_{\mathrm{SA}}$ denotes weight of space holder samples (i.e. starch acetate). $\rho_{\mathrm{Al}}$ and $\rho_{\mathrm{SA}}$ correspond to sample density under the same compacted condition for $\mathrm{Al}$ and starch acetate, respectively. $\mathrm{V}_{\mathrm{SA}}$ is the volume fraction of starch acetate. The porosity fraction $(\mathrm{Vp})$ of $\mathrm{Al}$ foam is expected to be equal to $\mathrm{V}_{\mathrm{SA}}$, and the porosity of foams containing no ADP is $52 \%$.

Micro-scale zone porosity morphologies of $\mathrm{Al}$ foam produced by powder sintering process are shown in Fig. 3(a). Figure 3(b) indicates the structure of a typical cell and the cell wall of $\mathrm{Al}$ foam. The cell size is approximately hundred microns. The produced cell geometry primarily hinges on the distribution of space holder particles in the process of mixing. The bonding region between two Al particles in the sample can be observed from Fig. 3(c), demonstrating the formation of strong bonding between $\mathrm{Al}$ particles. Figure 3(d) and (e) represent EDS analysis of the cell wall in the $\mathrm{Al}$ foam, indicating the existence of $\mathrm{Al}, \mathrm{O}$, and $\mathrm{C}$ in a large fraction, and $\mathrm{P}$ in a minor amount. Since the degradation of starch acetate begins at approximately $300^{\circ} \mathrm{C}$, carbonization and ash formation occur in the process of sintering. ${ }^{13)}$

From XRD patterns of the sintered $\mathrm{Al}$ foams shown in Fig. 4, the existence of $\mathrm{Al}$ phase can be observed even though these $\mathrm{Al}$ foams possess different contents of ADP. No obvious diffraction peaks of ADP phase is observed, which can be attributed to the transform of ADP powder to amorphous phase at initial sintering stage followed by a phase transition to form $\mathrm{Al}\left(\mathrm{PO}_{3}\right)_{3}$ at $500^{\circ} \mathrm{C}$, ${ }^{15)}$ or phosphate maybe too little to detect. In green compacts, ADP acts as a sintering additive locating between grains of $\mathrm{Al}$ and starch acetate or surrounding the $\mathrm{Al}$ grains, providing strength to prevent the powder metal structure from collapsing. Therefore, it is beneficial to bond $\mathrm{Al}$ grains together, and to prevent further oxidation during sintering process. As a thermosetting material, the cementation mechanism of ADP belongs to condensation polymerization. When heated, it decomposes, dehydrates and condenses. In addition, some 

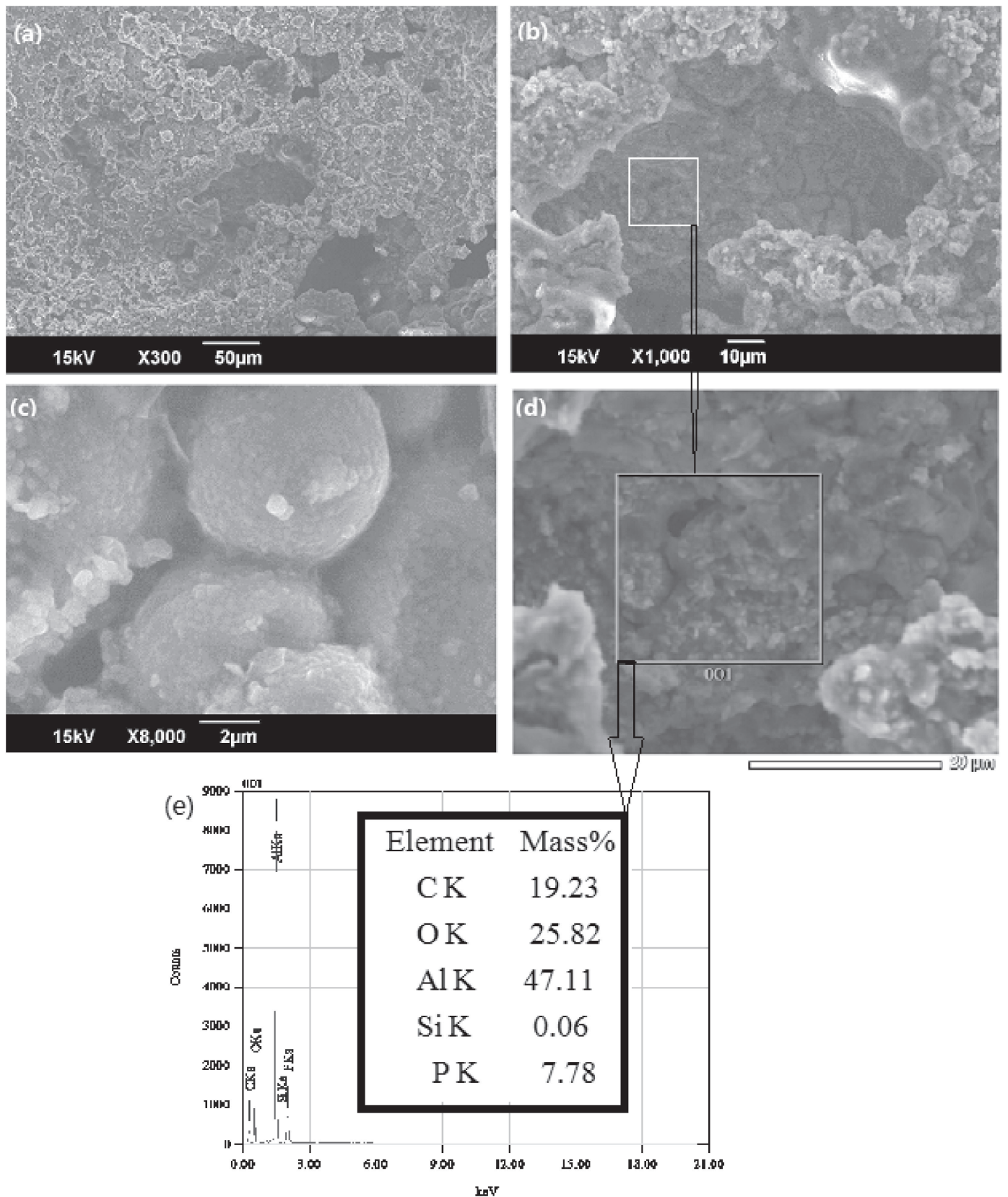

Fig. 3 SEM micrographs showing (a) micro-region structure of Al foams, (b) a cell and its wall, and (c) bonding between the Al particles,

(d)(e) EDS analysis of cell wall.

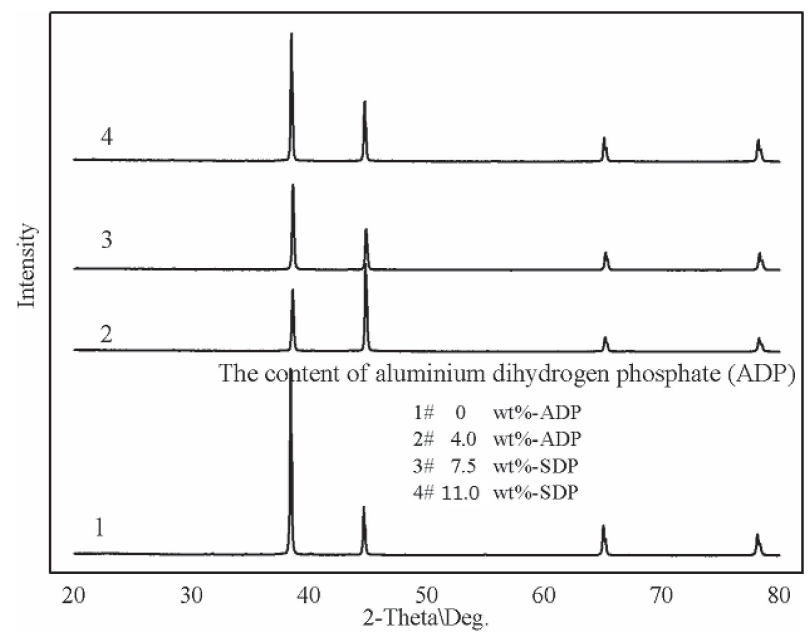

Fig. 4 X-ray diffraction patterns for the sintered $\mathrm{Al}$ foams with different contents of ADP. hydrogen may be produced from the reaction between $\mathrm{Al}$ and ADP, which would also be conducive to prevent $\mathrm{Al}$ oxidation at high temperature and increase porosity.

It is noteworthy that EDS data show the existence of carbon though no carbide peaks appears in XRD patterns in Fig. 4, suggesting that the produced carbon along the cell wall may exist in amorphous form after the process of annealing. Amorphous carbon along the cell wall may contribute to the enhancement of mechanical properties. ${ }^{16)}$ Certainly, it can be cleaned away by heating in air.

The relation between compressive stresses and strains of Al foams is shown in Fig. 5, and testing results indicate that $\mathrm{Al}$ foams with different $\mathrm{ADP}$ contents have same basic behaviors. All curves give expression to the representative behaviors of metallic foam stress-strain, which can be described as three regions. ${ }^{17)}$ The distinct zones, including initial elastic deformation, collapse plateau and densification 


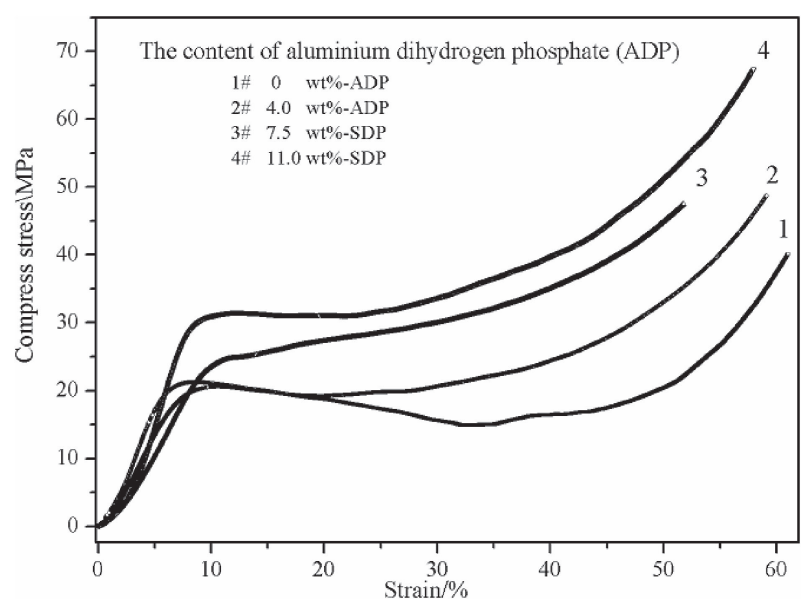

Fig. 5 Compressive stress-strain curves of Al foams with the increment of ADP weight fractions.

zone. From the plateau region, it can be observed that the curve is horizontal at the initial stage then a small positive slope, revealing that heavy plasticity deformation becomes dominant. Eventually, densification region is a compacting process where the cells touch each other, resulting in dramatical increasing in compressive stress. In present process of compression test, it can be observed that the cell walls of foam were collapsed in plateau region and fractured into pieces during the later densification stage. Comparing with pure $\mathrm{Al}$ foam, the composite $\mathrm{Al}$ foam (Al/ADP foam) added with ADP has increased compressive strength and plateau stress. The more the ADP is, the clearer these effects are. Obviously, stress of pure Al foam presents a trend of slightly fluctuating downward rather than a small positive slope of composite $\mathrm{Al}$ foams at the later stage of plateau region, suggesting poor bonding between $\mathrm{Al}$ particles in pure $\mathrm{Al}$ foam. This is due to the formation of unbroken oxide layer formed on the Al surface which prevents diffusion bonding in the process of sintering. Meanwhile, in plateau region, composite $\mathrm{Al}$ foams exhibit higher stresses than pure $\mathrm{Al}$ foam, which is attributed to the reinforcement of $\mathrm{Al}$ foams by products from heated ADP. However, the length of the plateau region becomes shorter by degrees as the ADP content is more than 7.5 mass $\%$, suggesting that the porosity content decreased with the gradually increasing content of ADP.

Energy absorption capabilities of foams with different ADP contents are shown in Fig. 6, which are calculated according to the equation:

$$
W=\int_{0}^{\varepsilon} \sigma d \varepsilon
$$

namely the area under the curves up to a certain strain. Energy absorption of foam relies mostly on the buckling, yielding, fracture and the friction of cell walls during the process of compressive deformation. ${ }^{18)}$ Energy absorption capacities of composite $\mathrm{Al}$ foams are found to increase with the increment of ADP content at any same strain, in accordance with compressive test results. Compared with pure Al foam, products from heated ADP are more suitable for the reinforcement because composite $\mathrm{Al}$ foams demonstrate excellent compressive mechanical properties

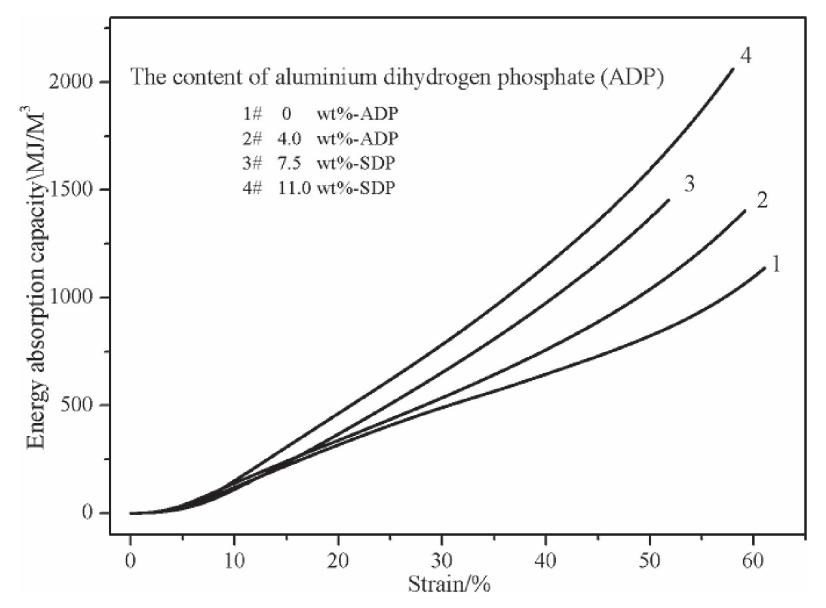

Fig. 6 Energy absorption capacity curves of the Al foams with increment of ADP weight fractions.

and energy absorption capacities. ADP additive was homogeneously embedded inside the Al powder, which is conducive to not only improving the interfacial bonding between $\mathrm{ADP}$ and $\mathrm{Al}$ matrix in green powder compact, but also promoting $\mathrm{Al}\left(\mathrm{PO}_{3}\right)_{3}$ serving as the bridge connection among the $\mathrm{Al}$ grains after sintering. The heated product of ADP formed in the cell wall is also beneficial for imposing restrictions on the deformation of the cell wall and enhances structural stability.

The decomposition of starch acetate during sintering process was adopted to manufacture $\mathrm{Al}$ foam with small open cell to improve the functions such as filtration, and energy or sound absorption. Although Al alloy oxide layers formed on the powder particles prevent diffusion bonding, ADP as a thermosetting material was used in present investigation, and the heated product acts as the bridge connection among $\mathrm{Al}$ particles to restrict cell wall deformation. The compressive test of the manufactured $\mathrm{Al}$ foam indicates that mechanical characteristics are largely affected by the content of ADP. ADP dispersed in Al matrix precursors with proper amount can strengthen bonding between $\mathrm{Al}$ powder, nevertheless, an excess of ADP (more than 7.5 mass \%) also would lead to the porosity content of $\mathrm{Al}$ foam become somewhat decrease.

\section{Conclusion}

Al foams with porosity of $52 \%$ were obtained utilizing starch acetate as a space holder. The porosity depends mainly on the decomposition of starch acetate during sintering. Carbon produced from starch acetate during annealing may exist in form of amorphous and is distributed along the cell wall. Compared with pure $\mathrm{Al}$ foam, composite foam with ADP undergoing sintering shows an increase in compressive yield strength and compressive strength, elevates the plateau stress, and exhibits more superior energy absorption capacity. Nevertheless, the length of the plateau region has been shorted by degree as the ADP content is more than 7.5 mass $\%$. The heated product of ADP as a binder in present investigation acts as the bridge connection among the $\mathrm{Al}$ powder to restrict the deformation of the cell wall and enhance structural stability. All of these factors contribute to 
the boost of the strength and the energy absorption capacities of the composite $\mathrm{Al}$ foams.

\section{Acknowledgements}

This research work is supported by the Chengdu Normal University Talent introduction scientific research special project (No. YJRC2015-3), the Major Project of Education Department in Sichuan (No. 16ZA0367) and the National Natural Science Foundation of China (No. 11647095).

\section{REFERENCES}

1) L.Y. Aguirre-Perales, I. Jung and R.A.L. Drew: Acta Mater. 60 (2012) 759-769.

2) D.P. Mondal, H. Jain, S. Das and A.K. Jha: Mater. Des. 88 (2015) 430 437.

3) B. Jiang, N.Q. Zhao, C.S. Shi, X.W. Du, J.J. Li and H.C. Man: Mater. Lett. 59 (2005) 3333-3336.

4) T. Shi, X. Chen, Y. Cheng and Y. Li: Mater. Trans. 58 (2017) 243-248.

5) A.V. Byakova, S.V. Gnyloskurenko and T. Nakamura: Mater. Trans. 58 (2017) 249-258.
6) J.R. Li, H.F. Cheng, J.L. Yu and F.S. Han: Mater. Sci. Eng. A 362 (2003) 240-248.

7) C.E. Wen, M. Mabuchi, Y. Yamada, K. Shimojima, Y. Chino and T. Asahina: Scr. Mater. 45 (2001) 1147-1153.

8) L.P. Lefebvre, J. Banhart and D.C. Dunand: Adv. Eng. Mater. 10 (2008) 775-787.

9) Y.Y. Zhao, T. Fung, L.P. Zhang and F.L. Zhang: Scr. Mater. 52 (2005) 295-298.

10) L. Peroni, M. Scapin, C. Fichera, D. Lehmbus, J. Weise, J. Baumeister and M. Avall: Compos Parts B 66 (2014) 430-442.

11) J. Jakubowicz, G. Admek and M. Dewidar: J. Porous Mater. 20 (2013) 1137-1141.

12) L. Chen, X. Li, L. Li and S. Guo: Curr. Appl. Phys. 7 (2007) e90-e93.

13) Y.X. Xu, V. Miladinov and M.A. Hanna: Cereal Chem. 81 (2004) 735740.

14) BS ISO 13314:2011, Mechanical testing of metals. Ductility testing. Compression test for porous and cellular metals.

15) M. Zhao and Y. Zhang: Procedia Eng. 27 (2012) 1313-1319.

16) T. Imai, S.L. Dong, I. Shigematsu, N. Saito and K. Suzuki: Mater. Sci. Forum 502 (2005) 201-204.

17) D.P. Mondal, M.D. Goel and S. Das: Mater. Sci. Eng. A 507 (2009) 102-109.

18) A. Ibrahim, F. Zhang, E. Otterstein and E. Burkel: Mater. Des. 32 (2011) 146-153. 